\title{
Segmental Chloride and Fluid Handling during Correction of Chloride-Depletion Alkalosis without Volume Expansion in the Rat
}

\author{
John H. Galla, Denise N. Bonduris, Steven L. Dumbauld, \\ and Robert G. Luke \\ Nephrology Research and Training Center, University of \\ Alabama in Birmingham, Birmingham, Alabama 35294
}

bstract. To determine whether chloride-depletion metabolic alkalosis (CDA) can be corrected by provision of chloride without volume expansion or intranephronal redistribution of fluid reabsorption, CDA was produced in Sprague-Dawley rats by peritoneal dialysis against $0.15 \mathrm{M} \mathrm{NaHCO}_{3}$; controls (CON) were dialyzed against Ringer's bicarbonate. Animals were infused with isotonic solutions containing the same $\mathrm{Cl}$ and total $\mathrm{CO}_{2}\left(\mathrm{tCO}_{2}\right)$ concentrations as in postdialysis plasma at rates shown to be associated with slight but stable volume contraction. During the subsequent $6 \mathrm{~h}$, serum $\mathrm{Cl}$ and $\mathrm{tCO}_{2}$ concentrations remained stable and normal in CON and corrected towards normal in CDA; urinary chloride excretion was less and bicarbonate excretion greater than those in CON during this period. Micropuncture and microinjection studies were performed in the $3 \mathrm{rd} \mathrm{h}$ after dialysis. Plasma volumes determined by ${ }^{125} \mathrm{I}$-albumin were not different. Inulin clearance and fractional chloride excretion were lower $(P<0.05)$ in CDA. Superficial nephron glomerular filtration rate determined from distal puncture sites was lower $(P<0.02)$ in CDA $(27.9 \pm 2.3 \mathrm{nl} / \mathrm{min})$ compared with that in CON (37.9 \pm 2.6$)$. Fractional fluid and chloride reabsorption in the proximal convoluted tubule and within the loop segment did not differ. Fractional chloride delivery to the early distal convolution did not differ but that out of this

The data herein were presented in part at the American Society of Clinical Investigation Annual Meeting, May 1982, Washington, DC, and published, in part, in the abstracts of the American Society of Nephrology Annual Meetings, 1981 and 1982.

Address all correspondence to Dr. Galla.

Received for publication 25 February 1983 and in revised form 1 August 1983.

J. Clin. Invest.

(c) The American Society for Clinical Investigation, Inc. $0021-9738 / 84 / 01 / 0096 / 11 \quad \$ 1.00$

Volume 73, January 1984, 96-106 segment was less $(P<0.01)$ in group CDA. Urinary recovery of ${ }^{36} \mathrm{Cl}$ injected into the collecting duct segment was lower $(P<0.01)$ in CDA (CON 74 \pm 3 ; CDA $34 \pm 4 \%)$.

These data show that CDA can be corrected by the provision of chloride without volume expansion or alterations in the intranephronal distribution of fluid reabsorption. Enhanced chloride reabsorption in the collecting duct segment, and possibly in the distal convoluted tubule, contributes importantly to this correction.

\section{Introduction}

Chloride-depletion metabolic alkalosis (CDA) ${ }^{1}$ is usually also associated with hypochloremia, hypokalemia, and sodium, chloride, potassium, and volume depletion. The relative contribution of the independent correction of each of these variables for the correction of alkalosis is controversial.

In a series of balance studies in dog and man, Schwartz and co-workers (1-4) showed that CDA produced by gastric drainage or nitrate loading could be corrected only by the administration of $\mathrm{NaCl}$ or $\mathrm{KCl}$ despite persisting potassium depletion. From these studies, Schwartz et al. (5) concluded that the provision of chloride is essential to the renal correction of CDA but the mechanism was unclear. In several of the aforementioned studies $(1,3)$, expansion of the extracellular fluid (ECF) volume after correction was calculated on the basis of chloride space (6).

In the dog that is rendered alkalotic by the administration of ethacrynic acid and a subsequent chloride-deficient diet, Cohen (7) showed that expansion of the ECF volume with isometric fluids (i.e., isotonic electrolyte solutions with an anion composition that approximated that of the plasma of the alkalotic animal) corrected metabolic alkalosis and he suggested that ECF volume expansion per se mediated the correction. He later sug-

1. Abbreviations used in this paper: $\mathrm{BW}$, body weight; CDA, chloridedepletion metabolic alkalosis (and experimental animals); CDS, collecting duct segment; CON, control animals; DCT, distal convoluted tubule; ECF, extracellular fluid; GFR, glomerular filtration rate; SNGFR, superficial nephron GFR; $\mathrm{tCO}_{2}$, total $\mathrm{CO}_{2}$; TF/UF, tubular fluid/ultrafiltrate; TGF, tubuloglomerular feedback; $\mathrm{UF}_{\mathrm{CL}}$, ultrafiltrate chloride concentration. 
gested that the expansion of the ECF volume alters the intranephronal distribution of fluid and sodium reabsorption ${ }^{2}$ to favor chloride reabsorption and correct CDA (8). In apparent contradiction of this hypothesis, Hulter et al. (9) showed that isometric volume expansion in dogs also corrects chronic hyperchloremic metabolic acidosis and suggested that the kidney selectively alters the anion composition of reabsorbate to correct the plasma acid-base composition. The dominance of volume homeostasis over acid-base balance has been most forcefully espoused by Schwartz and Cohen (10) who hypothesized that acid excretion by the kidney is determined by factors regulating the site and rate of sodium reabsorption and not by a homeostatic mechanism(s) that responds to systemic $\mathrm{pH}$.

In balance studies in the rat, we (11) have shown that complete correction of CDA produced by peritoneal dialysis occurs within $24 \mathrm{~h}$ by the oral intake of isotonic solutions of sodium or choline with chloride and bicarbonate concentrations that would only maintain alkalosis; chloride is retained by the kidney. Also in this model, CDA persisted for at least $7 \mathrm{~d}$ if chloride was eliminated from the diet. Correction occurred despite negative sodium and potassium balance, weight loss, and an obligatory bicarbonate load. From a conceptual standpoint, changes in plasma anion composition that correct CDA can be produced by the administration of chloride, by shifts of these anions between the intracellular and extracellular compartments, or by the excretion of bicarbonate and the conservation of chloride affected either by redistribution of fluid reabsorption or by alterations of anion transport within the various segments of the nephron.

The purpose of the present series of experiments was to determine: $(a)$ whether correction of CDA occurs during isometric intravenous infusions in the rat without volume expansion and, if so, $(b)$ which nephron segments participate in the process, and $(c)$ whether alterations in intranephronal fluid reabsorption are required. To accomplish these goals, micropuncture and microinjection studies were carried out in rats during correction of CDA by maintenance infusion of isotonic solutions with chloride and bicarbonate concentrations that approximate those of the plasma of chronic CDA rats.

\section{Methods}

An overview of our investigative approach follows. All animals were initially dialyzed. Infusion studies over $6 \mathrm{~h}$ determined the time course of correction in terms of plasma electrolytes and the maintenance infusion requirements necessary to avoid expansion of the ECF volume. Micropuncture and microinjection studies in the $3 \mathrm{rd} \mathrm{h}$ after dialysis were then performed in control animals (CON) and experimental animals (CDA)

2. Because of preferential bicarbonate reabsorption in the proximal tubule and preferential chloride reabsorption in the thick ascending limb of the loop of Henle, shifts of fractional fluid reabsorption from the thick ascending limb of the loop of Henle to the proximal tubule would favor bicarbonate reabsorption and vice versa. to determine fluid and chloride transport in the various nephron segments during correction.

Male Sprague-Dawley rats (Charles River Breeding Laboratories, Inc., Cambridge, MA) ate regular rat chow (Ralston Purina Co., St. Louis, MO) and drank tap water ad lib. before all studies. On the day of dialysis, rats were anesthetized with an intraperitoneal injection of Inactin, $100 \mathrm{mg} / \mathrm{kg}$ body weight (BW). The animals were placed on a heated board and their body temperatures were maintained at $37^{\circ} \mathrm{C}$. Warmed dialysate $(15 \mathrm{ml} / 100 \mathrm{~g} \mathrm{BW})$ was infused into the peritoneal cavity through an 18-gauge Intracath. CON animals were dialyzed against a solution composed (in meq/liter) of $\mathrm{Na}, 150 ; \mathrm{K}, 4 ; \mathrm{Cl}, 114 ; \mathrm{HCO}_{3}$, 25; acetate, 15 ; and glucose, $15 \mathrm{~g} /$ liter. In CDA animals, chloride-depletion alkalosis was produced by a dialysate composed (in milliequivalents per liter) of $\mathrm{Na}, 150 ; \mathrm{K}, 4 ; \mathrm{HCO}_{3}, 154$; and glucose, $15 \mathrm{~g} /$ liter. After 30 min, the dialysate was removed and the volume and concentrations of sodium, potassium, and chloride were determined.

To determine the effect of time, maintenance infusions, and surgical preparation on the changes induced by dialysis, rats were studied for 6 $\mathrm{h}$ after dialysis. In each experiment, two littermate rats which weighed 250-300 g were anesthetized. In the experimental rat, the femoral artery was catheterized with PE-50 tubing and an arterial blood sample obtained for hematocrit and plasma chloride and total $\mathrm{CO}_{2}\left(\mathrm{tCO}_{2}\right)$ concentration. This and subsequent blood samples were replaced quantitatively by volume with an erythrocyte suspension obtained from the littermate. Notwithstanding this procedure, blood samplings were held to a minimum. The littermate was bled by aortic puncture. Arterial $\mathrm{pH}$ and $\mathrm{PaCO}_{2}$, and plasma sodium, potassium, chloride, and $\mathrm{tCO}_{2}$ concentrations were determined on this sample for base-line values. The remainder of the blood was centrifuged and the supernatant plasma was removed. The erythrocytes were resuspended in a modified Krebs-Ringer's-bicarbonate solution which contained (in millimoles per liter) $\mathrm{Na}, 140$; $\mathrm{K}, 4 ; \mathrm{Ca}, 1 ; \mathrm{Mg}, 0.5 ; \mathrm{Cl}, 80 ; \mathrm{HCO}_{3}, 40 ; \mathrm{SO}_{4}, 0.5$; acetate, $24 ; \mathrm{PO}_{4}, 1.3$; glucose, 5.6 and bovine serum albumin, $60 \mathrm{~g} /$ liter to a packed cell volume of $45 \%$. The resultant suspension was gassed slowly with $95 \%$ $\mathrm{O}_{2}$ and $5 \% \mathrm{CO}_{2}$ in a $37^{\circ} \mathrm{C}$ water bath. In the experimental rat, a tracheostomy and two PE-50 jugular venous catheters were then placed. Peritoneal dialysis was carried out as described. To correct for dialysisrelated fluid shifts (12), $6 \%$ bovine serum albumin in the modified KrebsRinger's-bicarbonate solution was infused slowly in a volume of $1.0 \mathrm{ml} /$ $100 \mathrm{~g} \mathrm{BW}$ for each $5.5 \%$ change in hematocrit (mean volume: $0.51 \mathrm{ml}$ $\mathrm{CON}$ and $1.02 \mathrm{ml} \mathrm{CDA}$ ). Group CDA rats were then infused with the aforementioned modified Krebs-Ringer's-bicarbonate without albumin at $0.5 \mathrm{ml} / 100 \mathrm{~g} \mathrm{BW} / \mathrm{h}$ throughout the experiment and group CON rats with a standard Krebs-Ringer's-bicarbonate solution with chloride of 100 , acetate, 24 and $\mathrm{HCO}_{3}, 25 \mathrm{mmol} /$ liter. The bladder was catheterized with PE-50 tubing. The left kidney was exposed through a subcostal incision and placed in a Lucite cup as for micropuncture and the left ureter was catheterized with PE-50 tubing at the hilum. When the peritoneal cavity was entered, an undetermined small volume of fluid leaked out routinely in both groups. This fluid, a remainder from hypertonic dialysis, was not replaced. Furthermore, surgical fluid losses (13) were also not replaced to avoid expansion of ECF volume. After this surgical preparation, which required $\sim 60 \mathrm{~min}$, serial arterial samples were obtained for determination of chloride concentrations. The experiment was terminated with an aortic puncture, and arterial $\mathrm{pH}$ and $\mathrm{PaCO}_{2}$, and plasma sodium, potassium, chloride, and $\mathrm{tCO}_{2}$ concentrations were determined in this sample.

In separate groups of $\mathrm{CON}$ and CDA rats studied in pairs, serial urinary chloride and $\mathrm{tCO}_{2}$ excretions were determined during dialysis and preparative surgery and periodically thereafter. A bladder catheter 
was placed before dialysis and secured by sutures to prevent leakage of dialysate. Otherwise, the protocol was as described above. Excretion rates obtained during the dialysis period before catheterization of the left ureter were halved to obtain single kidney values. Thereafter, excretion rates apply to the left kidney exposed for micropuncture. The body weights for these groups (CON, 279 $\pm 6, n=9$; CDA, 279 $\pm 6, n=9$ ) did not differ $(P=\mathrm{NS})$.

Free-flow micropuncture studies. Animals were prepared and studied in a manner identical to that for the infusion studies with the following exceptions. Late proximal and early distal tubule puncture sites were selected by intravenous injections of $7.5 \%$ Food, Drug, and Cosmetic (FD and C) green (Keystone Aniline and Chemical Co., Chicago, IL). [Methoxy- ${ }^{3} \mathrm{H}$ ]inulin, $250 \mu \mathrm{Ci} / \mathrm{h}$, was infused in the maintenance infusion. The inulin was dialyzed against distilled water for $72 \mathrm{~h}$ before use (14). In the $3 \mathrm{rd} h$ after peritoneal dialysis, one to three late proximal and one to three early distal timed tubule fluid samples were obtained during two successive 30 -min clearance periods. The volume, ${ }^{3} \mathrm{H}$-activity, and chloride concentration were determined for each tubule fluid sample. At the midpoint of each clearance period, arterial samples were obtained for hematocrit and inulin and chloride concentrations. Urine was collected for determination of volume and sodium, potassium, chloride, and inulin concentrations. Final arterial sample was obtained for hematocrit and sodium, potassium, chloride, $\mathrm{tCO}_{2}$, and protein concentration. The body weights of these groups (CON, 281 $18, n=11$; CDA, $276 \pm 2 \mathrm{~g}, n=8)$ were not different $(P=\mathrm{NS})$.

Separate groups of CON and CDA rats were prepared in an identical manner and plasma volumes were determined by ${ }^{125} \mathrm{I}$-albumin in the middle of the clearance period.

Microinjection studies. Animals were prepared in a manner identical to that for the micropuncture studies. After surgical preparation, tubule puncture sites were localized by the transit time of intravenous boluses of $0.05 \mathrm{ml} 7.5 \% \mathrm{FD}$ and $\mathrm{C}$ green, which correlate well with microdissection (15). The difference between early and late distal convoluted tubule (DCT) transit times was used to compare the mean loci of punctures between groups (16) and did not differ (CON, 21.0 1.9 ; CDA, 21.2 \pm 1.8 $\mathrm{s} ; \boldsymbol{P}=\mathrm{NS})$. In the 3rd $\mathrm{h}$ after dialysis, two 15 -min clearance periods bracketed a 1-h period during which late DCTs were punctured. $8 \%$ polyfructosan was substituted for $\left[{ }^{3} \mathrm{H}\right]$ inulin in the maintenance infusion.

Fluid for microinjections was prepared with sodium chloride labeled with ${ }^{36} \mathrm{Cl}$ (Amersham Corp., Arlington Heights, IL) and [methoxy${ }^{3} \mathrm{H}$ ]inulin (New England Nuclear, Boston, MA). These isotopes were diluted with distilled water to yield radioactivities of $10 \mu \mathrm{Ci} / \mathrm{ml}$ of ${ }^{36} \mathrm{Cl}$ and $50 \mu \mathrm{Ci} / \mathrm{ml}$ of $\left[{ }^{3} \mathrm{H}\right]$ inulin. $2 \mathrm{nl}$ of $5 \%$ solution of $\mathrm{FD}$ and $\mathrm{C}$ green were added to $45 \mu$ l of injectate to tint the solution. The final chloride concentration of the injectate was $40 \mathrm{meq} / \mathrm{liter}$. 8-10-nl droplets of the labeled solution were placed under oil in a Petri dish with a constantvolume pipette and aspirated into an oil-filled micropipette. The radioactivity of three pipettings was counted directly to determine the activity of ${ }^{3} \mathrm{H}$ and ${ }^{36} \mathrm{Cl}$ injected. Injections into the collecting duct segment (CDS) were made slowly enough to avoid retrograde flow. The often quite low tubule fluid flow rate in the late DCT in group CDA rats dictated an injection time of $\sim 5 \mathrm{~min}$. The same 5-min injection time was used for group CON rats. For the $15 \mathrm{~min}$ after the initiation of the injection, urine was collected into scintillation vials that contained 0.5 $\mathrm{ml}$ of distilled water and $10 \mathrm{ml}$ Scintiverse (Fisher Scientific Co., Pittsburgh, PA). In preliminary studies, a collection of this duration was sufficient to recover all of the injected $\left[{ }^{3} \mathrm{H}\right]$ inulin, and 30 -s injections gave ${ }^{36} \mathrm{Cl}$ recovery $(73 \%)$ in group $\mathrm{CON}$ similar to that obtained with 5 -min injections. In random punctures, the microinjection pipette was left in place and a tubule fluid sample obtained from previously injected or, alternatively, from freshly punctured late DCT by the introduction of a column of Sudan black-stained paraffin oil four to five tubule diameters in length. Collections either were spontaneous or required slight suction to maintain the oil block. Timed collections of tubule fluid in which chloride concentration and volume were determined permitted the calculation of tubule fluid flow rate and chloride delivery rate. The body weights of these groups (CON, 268 $\pm 7, n=12$; CDA, $271 \pm 5 \mathrm{~g}, n=20)$ were not different $(P=\mathrm{NS})$.

To examine further the independent influences of chloride load or fluid flow rate on ${ }^{36} \mathrm{Cl}$ recovery in group $\mathrm{CDA}$, the chloride concentration of the injectate in several injections was increased to $100 \mathrm{peq} / \mathrm{nl}$, which approximated the chloride delivery to the CDS in group CON $(1,270$ peq) during the 5-min injection. Attempts to double the volume of injectate into group CDA to approximate the late DCT flow rate in group $\mathrm{CON}$ were unsuccessful due to backflow.

Analytical techniques. Activities of ${ }^{36} \mathrm{Cl}$ and $\left[{ }^{3} \mathrm{H}\right]$ inulin in tubule fluid, plasma, and urine were determined by liquid scintillation counting (Packard model 3325 Tri-Carb liquid scintillation spectrometer, Packard Instrument Co., Downers Grove, IL). Corrections were made for background activity and for crossover counts of ${ }^{36} \mathrm{Cl}$ into the ${ }^{3} \mathrm{H}$ channel in the appropriate samples. Quench corrections were obtained from an internal standard. Microinjection samples in which the recovery of $\left[{ }^{3} \mathrm{H}\right]$ inulin was $<93 \%$ or $>107 \%$ were discarded.

The volume of tubule fluid samples was measured in constant-bore glass tubing with a microslide comparator (Gaertner Scientific Corp., Chicago, IL). Tubule fluid chloride concentration was determined by the second method of Ramsay et al. (17).

In the microinjection series, inulin concentration in urine and plasma was determined by the anthrone method (18). Sodium and potassium concentrations in urine and plasma were determined by flame photometry (model 243, Instrumentation Laboratory, Inc., Lexington, MA) and chloride concentration by electrometric titration (Buchler Instruments, Inc., Fort Lee, $\mathrm{NJ}$ ). $\mathrm{tCO}_{2}$ concentration in plasma and urine was determined manometrically (Harleco $\mathrm{CO}_{2}$ apparatus, Dade Diagnostics Inc., Aquado, PR). Arterial $\mathrm{pH}$ and $\mathrm{CO}_{2}$ tension were determined with a BMS3 MK2 blood gas analyzer (Radiometer A/S, Copenhagen). Protein concentration was determined by refractometry (model 10400A, American Optical Corp., Buffalo, NY).

Plasma volume was estimated with ${ }^{125}$ I-bovine serum albumin by the method of Belcher and Harriss (19) with a correction for plasma trapping.

Calculations. Whole kidney glomerular filtration rate (GFR) and urinary excretions of sodium, potassium, and chloride were calculated according to standard expressions. The change in plasma volume based on serial hematocrits was calculated as previously described (20). Ultrafiltrate chloride concentration $\left(\mathrm{UF}_{\mathrm{C}}\right)$ was obtained by multiplying plasma chloride concentration by the correction factor for plasma water (1.06), as previously suggested $(21,22)$. The various single nephron functional characteristics (including superficial nephron GFR (SNGFR), absolute and fractional reabsorptions, and deliveries of fluid and chloride from both proximal and distal puncture sites) and estimated reabsorptions of fluid and chloride in the loop segment were calculated as previously described (23). Distally determined SNGFRs were used to calculate load to the loop segment. The term "loop segment" refers to the entire nephron segment between the latest proximal and earliest distal surface convolutions. Recovery of nuclide in microinjection studies was expressed as counts recovered divided by counts injected multiplied by 100 . Values given are mean \pm SEM. Statistical significance was assessed between groups with the unpaired $t$ test and within groups with the paired $t$ test (24). Significance was set at the $5 \%$ level. 


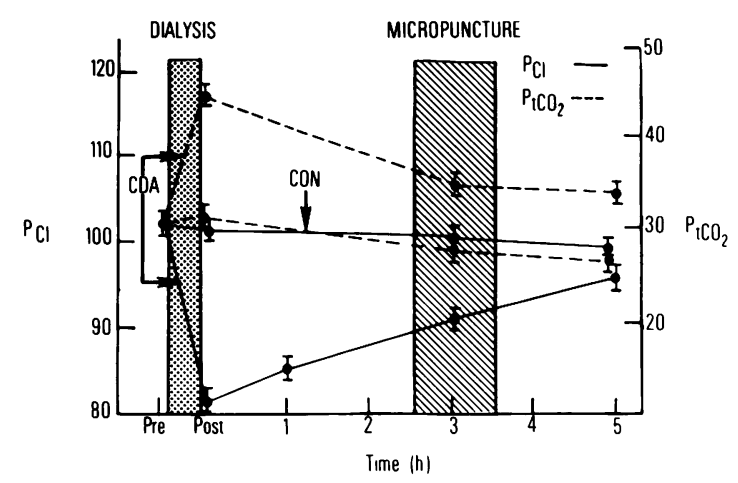

Figure 1. Changes in plasma chloride $\left(\mathrm{P}_{\mathrm{Cl}}\right.$, milliequivalents per liter) and $\mathrm{tCO}_{2}\left(\mathrm{P}_{1 \mathrm{tO}_{2}}\right.$, milliequivalents per liter) concentration in $\mathrm{CON}$ and CDA groups before and during $6 \mathrm{~h}$ of infusion. The dialysis period is indicated by the stippled bar and the micropuncture period by the hatched bar.

\section{Results}

Plasma chloride concentration in group $\mathrm{CON}$ was unaffected by dialysis and the 6-h infusion (Fig. 1; Tables I and II). In group CDA, plasma chloride concentration decreased $(P$ $<0.001)$ after dialysis and then increased during the isometric infusion toward $(P<0.001)$, but remained lower than $(P$ $<0.001$ ), the initial normal concentration at both 3 and $6 \mathrm{~h}$ after dialysis (Fig. 1). Serial urinary chloride concentrations and excretion rates were less in group CDA (Table III). Plasma $\mathrm{tCO}_{2}$ concentration in group CDA increased reciprocally $(P<0.001)$ after dialysis and then decreased toward $(P<0.001)$, but at 3 and $6 \mathrm{~h}$ after dialysis remained higher than $(P<0.01)$, the initial concentration. The predialysis plasma $\mathrm{tCO}_{2}$ in group $\mathrm{CON}$ that was slightly higher than the initial value obtained from littermates may be related to the initiation of maintenance infusions and the intervening surgical procedures. After dialysis, plasma $\mathrm{tCO}_{2}$ concentration in group $\mathrm{CON}$ remained slightly above base line, probably because of the acetate in the dialysate, it then declined $(P<0.05)$ to normal values by $3 \mathrm{~h}$ and remained stable thereafter. This probably accounts for the slight bicarbonaturia in group CON. Nevertheless, serial urinary $\mathrm{tCO}_{2}$ concentrations and excretions were greater in group CDA (Table III).

Mean arterial blood pressure did not differ between groups (Table II). Mean arterial hematocrits in both the infusion and micropuncture studies (Table IV) before and in the 1st, 3rd, and 6th $\mathrm{h}$ after dialysis did not differ between groups. Dialysis in group CDA induced greater volume contraction (at least in the micropuncture studies) that was successfully corrected to hematocrit levels not different from that in group CON in the $1 \mathrm{st} \mathrm{h}$. Subsequent serial hematocrits in both protocols did not change significantly within either group. $3 \mathrm{~h}$ after dialysis, hematocrits were higher $(P<0.01)$ than the initial hematocrits within both groups. On the basis of initial and 3rd-h hematocrits, plasma volume in the $3 \mathrm{rd} \mathrm{h}$ after dialysis had decreased ( $P$ $<0.001)$ in both groups; the estimated decrease in group CON $(-11.9 \pm 2.0 \%)$ was greater $(P<0.05)$ than that in group CDA $(-7.4 \pm 1.0 \%)$. However, the plasma volumes in the $3 \mathrm{rd} h$ de-

Table I. Plasma Electrolytes and Arterial Blood Gases before and Six $H$ after Dialysis

\begin{tabular}{|c|c|c|c|c|}
\hline & & \multicolumn{2}{|c|}{ Group } & \multirow[b]{2}{*}{$P$ value } \\
\hline & & CON & $\mathrm{CDA}$ & \\
\hline \multicolumn{5}{|l|}{ Plasma } \\
\hline \multirow[t]{2}{*}{$\mathrm{Na}^{+}($meq/liter $)$} & initial* $^{*}$ & \multicolumn{2}{|c|}{$143 \pm 1$} & \\
\hline & 6th $\mathrm{h}$ & $142 \pm 2$ & $142 \pm 1$ & NS \\
\hline \multirow[t]{2}{*}{$\mathrm{K}^{+}($meq/liter $)$} & initial* $^{*}$ & \multicolumn{2}{|c|}{$4.0 \pm 0.1$} & \\
\hline & 6th $\mathrm{h}$ & $4.2 \pm 0.1$ & $4.1 \pm 0.4$ & NS \\
\hline \multirow[t]{2}{*}{$\mathrm{Cl}$ (meq/liter) } & initial* $^{*}$ & \multicolumn{2}{|c|}{$99 \pm 1$} & \\
\hline & 6th $\mathrm{h}$ & $100 \pm 1$ & $96 \pm 2$ & NS \\
\hline \multirow[t]{2}{*}{$\mathrm{tCO}_{2}$ (meq/liter) } & initial* $^{*}$ & \multicolumn{2}{|c|}{$25 \pm 1$} & \\
\hline & 6th h & $25 \pm 1$ & $33 \pm 1$ & $<0.0001$ \\
\hline \multicolumn{5}{|l|}{ Arterial } \\
\hline \multirow[t]{2}{*}{$\mathrm{pH}$} & initial* $^{*}$ & \multicolumn{2}{|c|}{$7.42 \pm 0.01$} & \\
\hline & 6th h & $7.49 \pm 0.03$ & $7.60 \pm 0.01$ & $<0.001$ \\
\hline \multirow[t]{2}{*}{$\mathrm{PaCO}_{2}(m m H g)$} & initial* $^{*}$ & \multicolumn{2}{|c|}{$36.2 \pm 1.0$} & \\
\hline & 6th $\mathrm{h}$ & $26.8 \pm 2.4$ & $34.4 \pm 0.99$ & $<0.005$ \\
\hline
\end{tabular}

* Data obtained from littermates. 
Table II. Summary of Experimental Kidney Functions and Plasma Electrolytes $3 \mathrm{H}$ after Dialysis in Microinjection Studies

\begin{tabular}{|c|c|c|c|c|}
\hline & & \multicolumn{2}{|c|}{ Group } & \multirow[b]{2}{*}{$P$ value } \\
\hline & & $\begin{array}{l}\text { CON } \\
(n=12)\end{array}$ & $\begin{array}{l}\text { CDA } \\
(n=20)\end{array}$ & \\
\hline \multirow[t]{2}{*}{ Arterial pressure $(\mathrm{mmHg})$} & pre PD & $121 \pm 2$ & $120 \pm 2$ & NS \\
\hline & $3 \mathrm{rd} \mathrm{h}$ & $116 \pm 2$ & $118 \pm 2$ & NS \\
\hline \multirow[t]{3}{*}{ Plasma $\mathrm{tCO}_{2}$ (meq/liter) } & pre PD & $31 \pm 1$ & $30 \pm 1$ & NS \\
\hline & post PD & $32 \pm 1$ & $43 \pm 1$ & $<0.01$ \\
\hline & $3 \mathrm{rd} \mathrm{h}$ & $27 \pm 0.9$ & $33 \pm 1$ & $<0.01$ \\
\hline \multirow[t]{3}{*}{ Plasma Cl (meq/liter) } & pre PD & $99 \pm 1$ & $101 \pm 1$ & NS \\
\hline & post PD & $101 \pm 2$ & $79 \pm 1$ & $<0.01$ \\
\hline & $3 \mathrm{rd} \mathrm{h}$ & $103 \pm 1$ & $90 \pm 1$ & $<0.01$ \\
\hline Inulin clearance $(\mu \mathrm{l} / \mathrm{min})$ & & $1153 \pm 81$ & $901 \pm 70$ & $<0.05$ \\
\hline Urine flow rate $(\mu \mathrm{l} / \mathrm{min})$ & & $4.1 \pm 0.5$ & $4.1 \pm 0.3$ & NS \\
\hline Sodium excretion (neq/min) & & $561 \pm 159$ & $199 \pm 39$ & $<0.05$ \\
\hline Potassium excretion (neq/min) & & $1062 \pm 125$ & $1239 \pm 88$ & NS \\
\hline Chloride excretion (neq/min) & & $418 \pm 101$ & $16 \pm 2$ & $<0.01$ \\
\hline Fractional sodium excretion (\%) & & $0.40 \pm 0.13$ & $0.14 \pm 0.03$ & $<0.05$ \\
\hline Fractional chloride excretion (\%) & & $0.30 \pm 0.07$ & $0.02 \pm 0.01$ & $<0.01$ \\
\hline
\end{tabular}

termined by ${ }^{125} \mathrm{I}$-albumin spaces $(\mathrm{CON}, 3.74 \pm 0.24$; CDA, $3.77 \pm 0.22 \mathrm{ml} / 100 \mathrm{~g} \mathrm{BW} ; P=\mathrm{NS})$ and plasma protein concentrations (CON, $5.0 \pm 0.1 \mathrm{~g} / \mathrm{dl} ; \mathrm{CDA}, 5.2 \pm 0.1 ; P=\mathrm{NS}) \mathrm{did}$ not differ.

Inulin clearance and urinary sodium and chloride excretions in the microinjection studies were significantly lower in group CDA compared with group $\mathrm{CON}$ in the $3 \mathrm{rd} \mathrm{h}$ after dialysis (Table II). Plasma chloride and $\mathrm{tCO}_{2}$ concentrations in the micropuncture and microinjection studies in the $3 \mathrm{rd} \mathrm{h}$ after dialysis were similar to those in the infusion studies (Fig. 1). In the micropuncture studies of proximal and distal tubules during the $3 \mathrm{rd} \mathrm{h}$ after dialysis, the experimental kidney inulin clearance in CDA $(1,201 \pm 219 \mu \mathrm{l} / \mathrm{min})$ was also lower, although not significantly so $(P=\mathrm{NS})$, than that in CON $(1,461 \pm 135)$. To determine whether GFR returns to control values when CDA is completely corrected, separate groups of rats $(\mathrm{CON}, n=7$; CDA, $n=6$ ) were dialyzed in pairs, and upon awakening they were given low sodium chloride chow and drink containing $\mathrm{Na}$, 150; $\mathrm{Cl}, 70 ; \mathrm{HCO}_{3}, 40$; and acetate, $40 \mathrm{meq} / \mathrm{liter}$ ad lib. $24 \mathrm{~h}$ later, single kidney inulin clearances were not different (CON, $1,640 \pm 437$; CDA, $1,546 \pm 256 \mu \mathrm{l} / \mathrm{min}$ ) when both plasma $\mathrm{Cl}$ and $\mathrm{tCO}_{2}$ were not different from normal control values.

Mean SNGFR as determined from the latest proximal puncture sites did not differ between groups (Table V). However, mean SNGFR determined from earliest distal puncture sites was lower in group CDA compared with group CON.
Absolute and fractional fluid and chloride reabsorptions determined from proximal punctures did not differ (Table V). Superficial nephron fractional fluid and chloride reabsorptions up to the early DCT did not differ, whereas absolute fluid and chloride reabsorptions did. Because of a lower filtered load, absolute chloride delivery to the loop segment $(1,873 \pm 192$ peq/ $\mathrm{min})$ in group CDA was lower $(P<0.02)$ than that $(2,402 \pm 170$ $\mathrm{peq} / \mathrm{min}$ ) in group CON. The tubule fluid/ultrafiltrate (TF/UF) chloride ratios in the late proximal and early distal tubules did not differ (Table V).

In the loop segment, both absolute fluid $(n=15)$ and chloride $(n=9)$ reabsorptions were lower $(P<0.05$ and $<0.01$, respectively) in group CDA, whereas fractional reabsorptions did not differ (Fig. 2).

Fluid delivery to the early DCT did not differ $(\mathrm{CON}, 5.9 \pm 0.6$; CDA, $4.9 \pm 0.8 \mathrm{nl} / \mathrm{min} ; P=\mathrm{NS}$ ) between groups. Similarly, chloride delivery to DCT did not differ (CON, 191 \pm 37 ; CDA, $110 \pm 18 \mathrm{peq} / \mathrm{min} ; P=\mathrm{NS})$. However, chloride delivery out of the late DCT was less in group CDA (CON, 188 \pm 39 ; CDA, $72 \pm 8$ ) primarily because of a lower tubule fluid flow rate (Table VI).

Urinary recovery of ${ }^{36} \mathrm{Cl}$ injected into the $\mathrm{CDS}$ was higher in group CON than in group CDA (Table VI). Urinary ${ }^{36} \mathrm{Cl}$ recoveries in group CDA in injectates that contained chloride of $100 \mathrm{peq} / \mathrm{nl}$ and thus approximated the chloride delivery in CON remained less than those in group CON. Neither chloride 
Table III. Serial Urinary Chloride and $\mathrm{tCO}_{2}$ Concentrations and Excretion Rates in the Experimental Kidney

\begin{tabular}{|c|c|c|c|c|c|c|}
\hline \multirow[b]{2}{*}{ Period } & \multicolumn{2}{|c|}{ Urinary chloride } & \multirow[b]{2}{*}{$P$ value } & \multicolumn{2}{|c|}{ Urinary $\mathrm{tCO}_{2}$} & \multirow[b]{2}{*}{$P$ value } \\
\hline & CON & $\mathrm{CDA}$ & & CON & $\mathrm{CDA}$ & \\
\hline \multirow[t]{2}{*}{ Dialysis } & $166 \pm 28^{*}$ & $41 \pm 14$ & $<0.005$ & $19 \pm 5$ & $175 \pm 27$ & $<0.0001$ \\
\hline & $344 \pm 85 \ddagger$ & $233 \pm 59$ & NS & $47 \pm 12$ & $1320 \pm 305$ & $<0.01$ \\
\hline \multirow[t]{2}{*}{ Surgery } & $106 \pm 15$ & $4 \pm 1$ & $<0.0001$ & $45 \pm 11$ & $206 \pm 9$ & $<0.0001$ \\
\hline & $349 \pm 85$ & $53 \pm 20$ & $<0.01$ & $158 \pm 58$ & $2523 \pm 373$ & $<0.01$ \\
\hline \multirow[t]{2}{*}{ 2nd $h \S$} & $53 \pm 10$ & $4 \pm 1$ & $<0.0005$ & $47 \pm 14$ & $145 \pm 17$ & $<0.0005$ \\
\hline & $313 \pm 78$ & $47 \pm 15$ & $<0.01$ & $332 \pm 128$ & $1691 \pm 287$ & $<0.01$ \\
\hline \multirow[t]{2}{*}{ 4th $\mathrm{h}$} & $21 \pm 5$ & $3 \pm 1$ & $<0.005$ & $26 \pm 8$ & $71 \pm 18$ & $<0.05$ \\
\hline & $137 \pm 57$ & $26 \pm 8$ & NS & $205 \pm 100$ & $600 \pm 187$ & NS \\
\hline \multirow[t]{2}{*}{ 6th $\mathrm{h}$} & $14 \pm 4$ & $4 \pm 1$ & $<0.05$ & $19 \pm 5$ & $57 \pm 15$ & NS \\
\hline & $48 \pm 14$ & $25 \pm 9$ & NS & $85 \pm 34$ & $361 \pm 107$ & $<0.05$ \\
\hline
\end{tabular}

* Concentration in milliequivalents per liter.

$\ddagger$ Excretion rate in nanoequivalents per minute.

$\S$ Time after dialysis.

delivery into the CDS (Fig. 3) nor tubule fluid flow rate in the late DCT (Fig. 4) correlated ( $r=0.04$ and $r=0.01$, respectively; $P=\mathrm{NS}$ ) with simultaneously determined ${ }^{36} \mathrm{Cl}$ urinary recovery.

\section{Discussion}

Acute chloride-depletion alkalosis in the rat can be produced by peritoneal dialysis against isotonic $\mathrm{NaHCO}_{3}$; metabolic al- kalosis persists for at least $7 \mathrm{~d}$ if chloride is excluded from the diet (11). In the present series of experiments, chloride was given intravenously in a concentration less than that in plasma immediately after dialysis and with bicarbonate in a concentration adequate to preserve the alkalosis in the absence of corrective homeostatic responses. Volume expansion was avoided and plasma volumes did not differ between groups. Indeed, slight but stable volume contraction was maintained in both groups.

Table IV. Summary of Serial Hematocrits

\begin{tabular}{|c|c|c|c|c|c|c|c|}
\hline Group & $\begin{array}{l}\text { Pre- } \\
\text { dialysis }\end{array}$ & $\begin{array}{l}\text { Post- } \\
\text { dialysis }\end{array}$ & 1st h & $3 \mathrm{rd} \mathrm{h}$ & $\begin{array}{l}P \text { value } \\
\text { (Ist vs. } \\
\text { 3rd h) }\end{array}$ & 6th $\mathrm{h}$ & $\begin{array}{l}P \text { value } \\
\text { 3rd vs. } \\
\text { 6th } \mathrm{h}\end{array}$ \\
\hline & $\%$ & $\%$ & $\%$ & $\%$ & $\%$ & $\%$ & $\%$ \\
\hline \multicolumn{8}{|c|}{ Infusion experiments only } \\
\hline \multicolumn{8}{|l|}{ CON } \\
\hline$(n=11)$ & $41.8 \pm 0.5$ & $46.4 \pm 0.9$ & $44.1 \pm 0.8$ & $43.8 \pm 0.9$ & NS & $44.6 \pm 1.0$ & NS \\
\hline \multicolumn{8}{|l|}{ CDA } \\
\hline$(n=10)$ & $41.8 \pm 0.5$ & $47.6 \pm 0.8$ & $44.8 \pm 0.6$ & $43.3 \pm 0.6$ & NS & $43.2 \pm 0.6$ & NS \\
\hline$P$ value & NS & NS & NS & NS & NS & NS & \\
\hline \multicolumn{8}{|c|}{ Micropuncture and microinjection experiments } \\
\hline \multicolumn{8}{|l|}{$\mathrm{CON}$} \\
\hline$(n=19)$ & $41.8 \pm 0.4$ & $44.8 \pm 0.5$ & $43.4 \pm 0.6$ & $44.1 \pm 0.8$ & NS & - & - \\
\hline \multicolumn{8}{|l|}{ CDA } \\
\hline$(n=28)$ & $41.7 \pm 0.3$ & $47.5 \pm 0.3$ & $44.5 \pm 0.5$ & $44.0 \pm 0.6$ & NS & - & - \\
\hline$P$ value & NS & $<0.01$ & NS & NS & - & - & - \\
\hline
\end{tabular}


Table V. Summary of Single Nephron Fluid and Chloride Data from Late Proximal and Early Distal Micropunctures

\begin{tabular}{|c|c|c|c|}
\hline & \multicolumn{2}{|c|}{ Group } & \multirow[b]{2}{*}{$P$ value } \\
\hline & CON & CDA & \\
\hline \multicolumn{4}{|l|}{ Proximal } \\
\hline SNGFR $(n l / m i n)$ & $36.9 \pm 2.1(26)^{*}$ & $33.8 \pm 3.0(23)^{*}$ & NS \\
\hline $\mathrm{TF} / \mathrm{UF}_{\mathrm{Cl}}$ & $1.18 \pm 0.02$ & $1.18 \pm 0.02$ & NS \\
\hline Fluid reabsorption (\%) & $51.4 \pm 2.2$ & $53.3 \pm 3.2$ & NS \\
\hline Fluid reabsorption (nl/min) & $18.0 \pm 1.4$ & $16.8 \pm 2.2$ & NS \\
\hline Chloride reabsorption (\%) & $39.4 \pm 2.7$ & $37.7 \pm 3.8$ & NS \\
\hline Chloride reabsorption (peq/min) & $1,577 \pm 155$ & $1,300 \pm 192$ & NS \\
\hline \multicolumn{4}{|l|}{ Distal } \\
\hline SNGFR (nl/min) & $37.9 \pm 2.6(15)^{*}$ & $27.9 \pm 2.3(10)^{*}$ & $<0.02$ \\
\hline $\mathrm{TF} / \mathrm{UF}_{\mathrm{Cl}}$ & $0.30 \pm 0.03$ & $0.25 \pm 0.04$ & NS \\
\hline $\mathrm{TF}_{\mathrm{Cl}}(p e q / n l)$ & $32 \pm 3$ & $24 \pm 4$ & NS \\
\hline Fluid reabsorption (\%) & $84.2 \pm 1.4$ & $82.4 \pm 2.0$ & NS \\
\hline Fluid reabsorption $(\mathrm{nl} / \mathrm{min})$ & $32.0 \pm 2.4$ & $23.0 \pm 1.8$ & $<0.02$ \\
\hline Chloride reabsorption (\%) & $95.2 \pm 0.7$ & $95.5 \pm 0.9$ & NS \\
\hline Chloride reabsorption ( $\mathrm{peq} / \mathrm{min}$ ) & $3,844 \pm 266$ & $2,488 \pm 209$ & $<0.001$ \\
\hline
\end{tabular}

$\mathrm{TF}_{\mathrm{Cl}}$, tubular fluid chloride concentration.

* Number of observations in parentheses.

Nevertheless, plasma chloride concentration increased and plasma bicarbonate decreased progressively. During correction, significantly greater bicarbonaturia in group CDA persisted throughout the $6 \mathrm{~h}$ of observation. Chloride conservation and low fractional sodium and chloride excretions were associated with a reduced GFR but without detectable alterations in fractional fluid or chloride reabsorption in the proximal tubule or the loop segment. However, fractional chloride uptake within the CDS and, perhaps, in the DCT was accelerated.

GFR in the experimental kidney and in superficial nephrons determined from distal puncture sites were lower in group CDA,
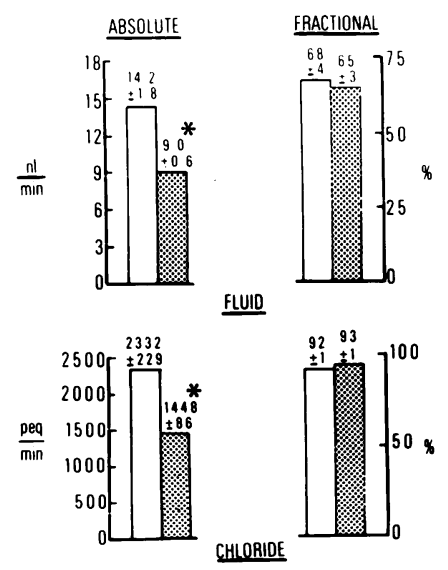

Figure 2. Absolute and fractional fluid and chloride reabsorption in the loop segment in CON (clear bars) and CDA (stippled bars) groups. ${ }^{*}, P<0.05 ;$ mean $\pm \mathrm{SE}$ is given over each bar.
78 and $74 \%$ of control, respectively. At the same time, mean arterial blood pressure and measured plasma volumes, arterial hematocrits, and plasma albumin concentrations did not differ between groups CON and CDA. The estimated decrement in plasma volume was actually greater in group $\mathrm{CON}$ which should, if anything, lead to a lower GFR. Although previous studies in the dog did not show significant differences in plasma creatinine concentrations (1) or creatinine clearances (3) between the alkalotic and corrected state, in a micropuncture study, Mello Aires and Malnic (25) reported lower inulin clearance in maintained CDA despite inulin spaces that did not differ in control and alkalotic rats. Thus, in agreement with previous studies in the rat, our data show a decreased GFR in alkalotic as compared with control rats not explained by differences in plasma volumes and mean arterial blood pressures.

The mechanism of the reduced GFR was not specifically investigated in this study. Nevertheless, within group CDA, proximally determined mean SNGFR did not parallel the decrement in experimental kidney GFR and was higher $(P<0.05)$ than that determined from distal punctures; this suggests interruption of tubuloglomerular feedback (TGF). Considering the signal for TGF, Bell and Navar (26) have reported that luminal osmolality in the earliest distal convolution is inversely correlated with SNGFR while others have argued that either chloride transport dependent upon luminal $\mathrm{Cl}$ concentration at the macula densa (27) or absolute chloride reabsorption within the loop segment (28) acts as the TGF signal and is inversely correlated with SNGFR. We have previously shown in rats infused with $\mathrm{NaHCO}_{3}$ that decreased chloride delivery to and 
Table VI. Summary of Late Distal Micropuncture and Microinjection Data

\begin{tabular}{lccl}
\hline & \multicolumn{2}{c}{ Group } \\
\cline { 2 - 3 } & CON & CDA & \\
\hline Tubule fluid flow rate $(\mathrm{nl} / \mathrm{min})$ & $6.3 \pm 0.9(23)^{*}$ & $2.9 \pm 0.4(26)$ & $<0.01$ \\
$\mathrm{Cl}$ concentration $(p e q / \mathrm{nl})$ & $29.4 \pm 3.7$ & $26.6 \pm 2.6$ & $\mathrm{NS}$ \\
$\mathrm{Cl}$ delivery to CDS $(p e q / \mathrm{min})$ & $188 \pm 39$ & $72 \pm 8$ & $<0.01$ \\
${ }^{3} \mathrm{H}$ recovery (\%) $\quad(40 \mathrm{peq} / \mathrm{nl}) \ddagger$ & $95.5 \pm 0.9(11)$ & $97.0 \pm 0.9(20)$ & $\mathrm{NS}$ \\
${ }^{36} \mathrm{Cl}$ recovery (\%) & $73.7 \pm 2.6$ & $33.9 \pm 3.8$ & $<0.01$ \\
${ }^{3} \mathrm{H}$ recovery (\%) $(100 \mathrm{peq} / \mathrm{nl}) \ddagger$ & - & $95.4 \pm 1.1(8)$ & $\mathrm{NS} \S$ \\
${ }^{36} \mathrm{Cl}$ recovery (\%) & - & $41.5 \pm 7.7$ & $\mathrm{NS} \S$ \\
\hline
\end{tabular}

* Number of observations.

$¥$ Chloride concentration of the injectate.

$\S$ Compared with $40 \mathrm{peq} / \mathrm{nl}$ injectate within group CDA.

concomitantly decreased absolute chloride reabsorption in the loop segment, such as seen in group CDA, were associated with increased osmolality but decreased chloride concentration in early distal tubule fluid (23). In preliminary studies in rats handled identically to groups CON and CDA, we have found early distal tubule fluid osmolality higher $(P<0.01)$ in group CDA $(142 \pm 6 \mathrm{mosmol} / \mathrm{kg})$ than that in group CON $(101 \pm 8 \mathrm{mosmol} /$ $\mathrm{kg})$. Since the plasma bicarbonate concentration was high and proximal tubule tubular fluid/plasma inulin and TF/UF chloride were not different from control, we assume that the bicarbonate concentration in tubule fluid delivered to the loop segment is higher than normal and, therefore, that the impermeance of bicarbonate in the thick ascending limb of Henle's loop (29, 30) probably accounts for these findings. If TGF is the mechanism by which GFR is reduced in CDA, our data would be most compatible with luminal osmolality as the signal, particularly since luminal chloride concentration and absolute chloride reabsorption in the loop segment (the other two proposed signals) were actually lower in CDA rats with a lower SNGFR.

The CDS avidly retained chloride in group CDA rats as shown by the reduced recovery of ${ }^{36} \mathrm{Cl}$, which was unrelated to tubule fluid flow rate or chloride delivery. Although ${ }^{36} \mathrm{Cl}$ uptake by microinjection provides only a semiquantitative index of unidirectional chloride flux, these indices agree in direction with net fractional chloride reabsorptions in the CDS of $99 \%$ in group $\mathrm{CDA}$ and $92 \%$ in group $\mathrm{CON}{ }^{3}$ We have previously provided evidence that hypochloremia per se accelerates chloride uptake in this segment (16). To the extent that determinations from the late distal segment of superficial nephrons are representative of delivery of fluid and solute from deeper nephrons, the observations in the present study are consistent with our earlier

3. If chloride delivery to the CDS, as determined in the microinjection studies, is assumed to be the same for the 30,000 nephrons of a rat kidney, estimated absolute chloride reabsorption in the CDS is 5,640 $\mathrm{neq} / \mathrm{min}$ less urinary chloride excretion of $418 \mathrm{neq} / \mathrm{min}$ and $2,160 \mathrm{neq} /$ min less $16 \mathrm{neq} / \mathrm{min}$ for groups $\mathrm{CON}$ and CDA, respectively. findings. In their study of maintained CDA, Mello Aires and Malnic (31) also showed that fractional chloride/inulin fluid/ plasma ratios were decreased only in urine and suggested that metabolic alkalosis accelerates chloride reabsorption in the CDS. In direct micropuncture studies of the rat papilla, Diezi and coworkers (32) showed enhancement of chloride uptake in the chloride-deprived rat in the collecting duct and suggested that chloride transport in this segment is active. Although tubule fluid flow rate or chloride delivery did not correlate with ${ }^{36} \mathrm{Cl}$ uptake in the CDS, both of these variables were lower in the alkalotic rats. Since DuBose et al. (33) have shown that chloride load to the CDS is positively correlated with fractional chloride excretion in the urine, the lower chloride delivery in CDA may also serve to promote chloride conservation in the CDS.

The proximal convoluted tubule and the loop segment separately and together had similar fractional chloride reabsorptions in both CON and CDA groups, observations that are in essential agreement with previous micropuncture studies of maintained CDA. Mello Aires and Malnic (31) found no differences in late proximal and early distal fractional chloride reabsorptions between control and alkalotic rats. More recently, Cogan (34) also concluded that superficial proximal tubule chloride reabsorption is not accelerated during metabolic alkalosis. Taken together, our observations and those of others suggest that intrinsic changes in reabsorption within the proximal tubule and loop of Henle do not contribute importantly to enhanced chloride reabsorption during correction of hypochloremia in CDA.

Alterations in chloride reabsorption in response to various maneuvers have not been extensively studied in the DCT. However, Sheth and co-workers (35) have shown that the DCT is an important site for adjustments in chloride balance during volume expansion. Although the micropuncture data from the early and late DCT were obtained in separate groups of rats in this study, fractional reabsorption of delivered chloride in the DCT in group CDA (estimated by subtracting chloride delivery out of from delivery into the DCT) is $34.5 \%$ compared with $1.6 \%$ in group CON. Moreover, if the filtered chloride loads for 


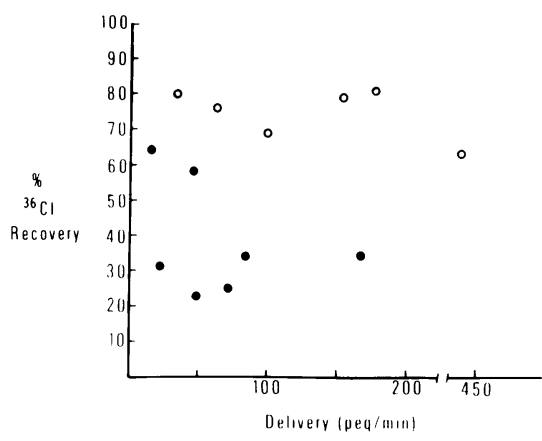

Figure 3. Relationship between urinary ${ }^{36} \mathrm{Cl}$ recovery and chloride delivery to the collecting duct segment in CON $(O)$ and CDA (๑) groups. The correlation coefficient $(r)$ is 0.04 .

groups $\mathrm{CON}$ and CDA are considered representative for both the micropuncture and microinjection series, fractional chloride delivery to the DCT did not differ (CON, 4.8 $\pm 0.8 \%$; CDA, $4.5 \pm 0.9 \% ; P=\mathrm{NS})$, whereas chloride delivery out of the DCT did differ (CON, 4.8 $\pm 1.0 \%$; CDA, $2.9 \pm 0.3 \% ; P=0.05)$. Both of these estimates suggest enhanced fractional chloride uptake in the DCT. These observations for the CDS and the DCT are consistent with several earlier observations and proposals (36-39).

The mechanism(s) by which these adjustments for chloride reabsorption are made in the DCT is speculative. The variability in the absolute delivery of chloride to the DCT in control rats may have masked significant differences between the groups. Thus, we cannot separate the roles of delivery and enhanced intrinsic chloride uptake, but suspect that both may contribute.

Our data also show that alterations in the intranephronal distribution of fluid reabsorption are unnecessary during correction. Specifically, fractional fluid reabsorptions did not differ at the late proximal or early distal tubule or within the loop segment. Mello Aires and Malnic (25) also found no differences in late proximal or early distal tubular fluid/plasma inulin ratios although their animals were studied during infusion of $5 \%$ mannitol in isotonic $\mathrm{NaHCO}_{3}$ at $5 \mathrm{ml} / \mathrm{h}$. Thus, in different models of alkalosis in the rat, no redistribution of intranephronal fluid reabsorption has been detected and, at least in the rat, recovery from CDA can proceed without such adjustments.

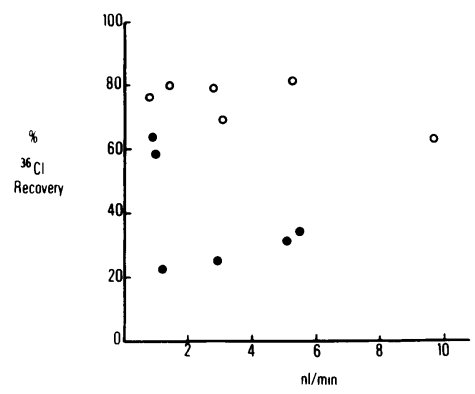

Figure 4. Relationship between urinary ${ }^{36} \mathrm{Cl}$ recovery and late distal tubule fluid flow rate in $\operatorname{CON}(O)$ and CDA $(\bullet)$ groups. The correlation coefficient $(r)$ is 0.01 .
Metabolic alkalosis may stimulate the production and excretion of other organic anions $(40,41)$, alter intestinal anion transport (42), and lead to shifts in anions between extracellular and intracellular spaces (43). Our studies do not address these possible extrarenal homeostatic mechanisms but on the basis of our estimates of plasma volume, net intercompartmental fluid shifts do not appear to participate detectably in the correction of plasma anion composition.

Arterial $\mathrm{CO}_{2}$ tensions were lower than normal $(36 \pm 1 \mathrm{mmHg})$ in both groups CON $(27 \pm 2)$ and CDA $(34 \pm 1)$ and thus merit comment. We attribute the lower $\mathrm{PaCO}_{2}$ to diaphragmatic stimulation by both peritoneal dialysis and mechanical retraction for exposure of the kidney for micropuncture. The effect of acute changes in $\mathrm{PaCO}_{2}$ on chloride reabsorption has not been extensively studied. Warren et al. (39) showed that rats inspiring $12 \% \mathrm{CO}_{2}$ had no change in proximal TF/UF chloride ratios or in urinary chloride excretion until at least $3 \mathrm{~h}$ of exposure; they did not study hypocapnia. Jacobson (44) has shown that chloride reabsorption in the isolated perfused proximal tubule of the rabbit is enhanced when exposed to a $\mathrm{CO}_{2}$ tension of $15 \mathrm{mmHg}$. It seems unlikely that a 7-mmHg difference in $\mathrm{PaCO}_{2}$ can explain the correction of the plasma $\mathrm{Cl}$ and $\mathrm{tCO}_{2}$ concentrations toward normal. Since group CON had the greater degree of hypocapnia, we would have expected progressive and greater increments in plasma chloride concentration, and a lower proximal TF/UF chloride ratio in group CON. Since none of these differences was seen and plasma chloride concentration remained stable in group $\mathrm{CON}$, we suggest that the small difference in $\mathrm{PaCO}_{2}$ does not contribute importantly to chloride reabsorption in this experimental setting.

In summary, acute chloride-depletion alkalosis in the rat can be corrected by the provision of chloride and without volume expansion or alterations in intranephronal fluid reabsorption. During correction, the renal contribution to correction of hypochloremia is achieved by enhanced fractional reabsorption of chloride in the collecting duct and probably the distal convoluted tubule and, in part, by a reduction in filtered chloride.

How might these observed differences in renal functions contribute to homeostasis-especially for sodium-in the maintenance phase of CDA? Since the delivery of excessive amounts of bicarbonate beyond the proximal tubule is likely to result in bicarbonaturia and sodium depletion, any reduction in GFR will decrease delivery of $\mathrm{HCO}_{3}$ out of the proximal tubule and thus tend to prevent such losses. Nevertheless, such filtration-mediated decrements in $\mathrm{HCO}_{3}$ delivery in maintenance CDA are counterbalanced by an elevated plasma bicarbonate. Since it is poorly reabsorbed in the loop of Henle $(29,30)$, any additional bicarbonate delivered out of the proximal tubule will be presented to distal sites, which have a limited capacity for reabsorption. We have previously shown that CDA, such as in the present study, is a potent stimulus to renin release (12), and, presumably would lead to enhanced aldosterone secretion which would, in turn, serve to accelerate bicarbonate reabsorption at sites beyond the loop segment. In addition, Stone et al. (45) have recently reported that decreased luminal chloride concen- 
tration independently of sodium increases bicarbonate reabsorption in the medullary collecting duct. All of these mechanisms that maintain alkalosis and conserve sodium are not dependent on sodium or volume depletion but on chloride depletion alone. Thus, it is possible that CDA in the rat may not necessarily be associated with concomitant sodium depletion. Previous data $(16,32)$ as well as the present experiments show that chloride depletion enhances chloride uptake in the collecting duct and perhaps the distal convoluted tubule. Subsequent repletion of chloride, in this schema, would allow the distal nephron to restore acid/base balance without the necessity of volume expansion and, indeed, even in the presence of slight but significant volume contraction, although the precise signals that evoke these alterations in anion transport have not been established.

None of the aforementioned mechanisms excludes the possibility that, when concomitant volume depletion accompanies CDA, additional processes including the intranephronal redistribution of fluid reabsorption promote renal conservation of sodium and bicarbonate. Nevertheless, the notion that chloride depletion, per se, can alter renal function so as to maintain alkalosis and fluid volume brings us full circle to an earlier position of Gulyassy et al. (1) “. . . provision of chloride was the factor critical to the corrective process (for metabolic alkalosis)."

\section{Acknowledgments}

We thank Beverly Booker and Meredith Holland for their excellent technical assistance and Carol Peterson for her excellent secretarial assistance.

This study was supported by National Institutes of Health grant 5-R01-AM26698.

\section{References}

1. Gulyassy, P. F., C. van Ypersele de Strihou, and W. B. Schwartz 1962. On the mechanism of nitrate-induced alkalosis. The possible role of selective chloride depletion in acid-base regulation. J. Clin. Invest. 41:1850-1862.

2. Kassirer, J. P., P. M. Berkman, D. R. Lawrenz, and W. B. Schwartz. 1965. The critical role of chloride in the correction of hypokalemic metabolic alkalosis in man. Am. J. Med. 38:172-189.

3. Needle, M. A., G. J. Kaloyanides, and W. B. Schwartz. 1964. The effects of selective depletion of hydrochloric acid on acid-base and electrolyte equilibrium. J. Clin. Invest. 43:1836-1846.

4. Kassirer, J. P., and W. B. Schwartz. 1966. Correction of metabolic alkalosis in man without repair of potassium deficiency. Am. J. Med. 40:19-26.

5. Schwartz, W. B., C. van Ypersele de Strihou, and J. P. Kassirer. 1968. Role of anions in metabolic alkalosis and potassium deficiency. N. Engl. J. Med. 279:630-639.

6. Atkins, E. L., and W. B. Schwartz. 1962. Factors governing correction of the alkalosis associated with potassium deficiency; the critical role of chloride in the recovery process. J. Clin. Invest. 41:218-229.

7. Cohen, J. J. 1968. Correction of metabolic alkalosis by the kidney after isometric expansion of extracellular fluid. J. Clin. Invest. 47:11811192.

8. Cohen, J. J. 1970. Selective $\mathrm{Cl}^{-}$retention in repair of metabolic alkalosis without increasing filtered load. Am. J. Physiol. 218:165-170.

9. Hulter, H. N., L. P. Ilnicki, J. A. Harbottle, and A. Sebastian. 1978. Correction of metabolic acidosis by the kidney during isometric expansion of extracellular fluid volume. J. Lab. Clin. Med. 92:602-612.

10. Schwartz, W. B., and J. J. Cohen. 1978. The nature of the renal response to chronic disorders of acid-base equilibrium. Am. J. Med. $64: 417-428$.

11. Galla, J. H., D. N. Bonduris, and R. G. Luke. 1983. Correction of acute chloride-depletion alkalosis in the rat without volume expansion. Am. J. Physiol. 244:F217-F221.

12. Abboud, H. E., R. G. Luke, J. H. Galla, and T. A. Kotchen. 1979. Stimulation of renin by acute selective chloride depletion in the rat. Circ. Res. 44:815-821.

13. Maddox, D. A., D. C. Price, and F. C. Rector, Jr. 1977. Effects of surgery on plasma volume and salt and water excretion in rats. Am. J. Physiol. 233:F600-F606.

14. Schafer, J. A., S. L. Troutman, and T. E. Andreoli. 1974. Volume reabsorption, transepithelial potential differences, and ionic permeability properties in mammalian superficial proximal straight tubules. J. Gen. Physiol. 64:582-607.

15. Wright, F. S. 1971. Increasing magnitude of electrical potential along the renal distal tubule. Am. J. Physiol. 220:624-638.

16. Kirchner, K. A., J. H. Galla, and R. G. Luke. 1980. Factors influencing chloride reabsorption in the collecting duct segment of the rat. Am. J. Physiol. 239:F552-F559.

17. Ramsay, J. A., R. H. J. Brown, and P. C. Croghan. 1955. Electrometric titration of chloride in small volumes. J. Exp. Biol. 32:822829.

18. Fuhr, J., J. Kaczmarczyk, and C. D. Kruttgen. 1955. Eine einfache colorimetrische Methode zur Inulinbestimmung fur Nieren-Clearance-Untersuchungen bei Stoffwechselgesunden und Diabetikern. Klin. Wochschr. 33:729-730.

19. Belcher, E. H., and E. B. Harriss. 1957. Studies of plasma volume, red cell volume and total blood volume in young growing rats. J. Physiol. (Lond.). 139:64-78.

20. Galla, J. H., J. E. Beaumont, and R. G. Luke. 1977. Effect of volume expansion with $\mathrm{NaCl}$ or $\mathrm{NaHCO}_{3}$ on nephron fluid and $\mathrm{Cl}$ transport. Am. J. Physiol. 233:F118-F125.

21. Harris, C. A., P. G. Baer, E. Chirito, and J. H. Dirks. 1974. Composition of mammalian glomerular filtrate. Am. J. Physiol. 227:972976.

22. Malnic, G., M. Mello Aires, and F. Lacaz Vieira. 1970. Chloride excretion in nephrons of rat kidney during alterations of acid-base equilibrium. Am. J. Physiol. 218:20-25.

23. Galla, J. H., K. A. Kirchner, T. A. Kotchen, and R. G. Luke. 1981. Effect of hypochloremia on loop segment chloride and solute reabsorption in the rat during volume expansion. Kidney Int. 20:569574.

24. Snedecor, G. W., and W. G. Cochran. 1980. Statistical Methods. Seventh ed. Iowa State University Press, Ames. 54-233.

25. Mello Aires, M., and G. Malnic. 1972. Renal handling of sodium and potassium during hypochloremic alkalosis in the rat. Pfluegers Arch. 331:215-225.

26. Bell, P. D., and L. G. Navar. 1982. Relationship between tubuloglomerular feedback responses and perfusate hypotonicity. Kidney Int. 22:234-239.

27. Schnermann, J., and J. Briggs. 1982. Concentration-dependent 
sodium chloride transport as the signal in feedback control of glomerular filtration rate. Kidney Int. 22(Suppl. 12):S82-S89.

28. Blantz, R. C., and K. S. Konnen. 1977. Relation of distal tubular delivery and reabsorptive rate to nephron filtration. Am. J. Physiol. 233:F315-F324.

29. Iino, Y., and M. B. Burg. 1981. Effect of acid-base status in vivo on bicarbonate transport by rabbit renal tubules in vitro. Jap. J. Physiol. 31:99-107.

30. Seldin, D. W., J. M. Rosin, and F. C. Rector, Jr. 1975. Evidence against bicarbonate reabsorption in the ascending limb, particularly as disclosed by free-water clearance studies. Yale J. Biol. Med. 48:337347.

31. Mello Aires, M., and G. Malnic. 1972. Micropuncture study of acidification during hypochloremic alkalosis in the rat. Pfluegers Arch. 331:13-24

32. Diezi, J., P. Michoud, J. Aceves, and G. Giebisch. 1973. Micropuncture study of electrolyte transport across papillary collecting duct of the rat. Am. J. Physiol. 224:623-634.

33. DuBose, T. D., Jr., D. W. Seldin, and J. P. Kokko. 1978. Segmental chloride reabsorption in the rat nephron as a function of load. Am. J. Physiol. 234:F97-F105.

34. Cogan, M. G. 1981. Proximal reabsorption during metabolic alkalosis. Abstracts 8th International Congress of Nephrology. 31.

35. Sheth, A. U., T. F. Knight, E. Pace, H. O. Senekjian, and E. J. Weinman. 1981. Segmental chloride reabsorption during volume expansion and recovery. Am. J. Physiol. 240:F395-F399.

36. Rector, F. C., Jr., and J. R. Clapp. 1962. Evidence for active chloride reabsorption in the distal renal tubule of the rat. J. Clin. Invest. 41:101-107.
37. Windhager, E. E., and G. Giebisch. 1965. Electrophysiology of the nephron. Physiol. Rev. 45:214-244.

38. Luke, R. G., Y. Warren, M. Kashgarian, and H. Levitin. 1970. Effects of chloride restriction and depletion on acid-base balance and chloride conservation in the rat. Clin. Sci. (Lond.). 38:385-396.

39. Warren, Y., R. G. Luke, M. Kashgarian, and H. Levitin. 1970 Micropuncture studies of chloride and bicarbonate absorption in the proximal renal tubule of the rat in respiratory acidosis and in chloride depletion. Clin. Sci. (Lond.). 38:375-383.

40. Gordon, E. E. 1963. Effect of acute metabolic acidosis and alkalosis on acetate and citrate metabolism in the rat. J. Clin. Invest. 43:137-142.

41. Simpson, D. P., and S. R. Hager. 1979. pH and bicarbonate effects on mitochondrial anion accumulation. Proposed mechanism for changes in renal metabolite levels in acute acid-base disturbances. $J$. Clin. Invest. 63:704-712.

42. Feldman, G. M., and A. N. Charney. 1980. Effect of acute metabolic alkalosis and acidosis on intestinal electrolyte transport in vivo. Am. J. Physiol. 239:G427-G436.

43. Garella, S., C. L. Dana, and J. A. Chazan. 1973. Severity of metabolic acidosis as a determinant of bicarbonate requirements. $N$. Engl. J. Med. 289:121-126.

44. Jacobson, H. R. 1981. Effects of $\mathrm{CO}_{2}$ and acetazolamide on bicarbonate and fluid transport in rabbit proximal tubules. Am. J. Physiol. 240:F54-F62.

45. Stone, D. K., D. W. Seldin, J. P. Kokko, and H. R. Jacobson. 1983. Anion dependence of rabbit medullary collecting duct acidification. J. Clin. Invest. 71:1505-1508. 